\title{
An Account of Rise and fall of Transformational Generative Grammar TGG: A Descriptive Study
}

\author{
Ahmed Mohammed Saleh Alduais ${ }^{1 *}$
}

\section{ABSTRACT}

Purpose: To account for the rise and fall of transformational generative grammar (TGG).

Method: The researcher followed a descriptive research approach where the presentation of this paper is totally based on previous studies accounting for TGG.

Results: There were many reasons for the rise of TGG including: innovativeness of this approach, its presentation in relation to other fields like mathematics a logic, providing more reasonable answers for controversial issue in regard to language, etc.. On the other hand, there were many reason that have lead to the fall of this approach including: ambiguity resulting from integration with other fields, namely mathematics and logic, rise of sub-schools most importantly generative semantics, frequent modifications of the proposed theory, etc..

Conclusions: In spite of the fact that TGG was able to approach language innovatively but it seemed clearly to link human cognitive abilities to the proposed theory. More focus was based on the sentence level ignoring meaning and text.

Keywords: Transformational Generative Grammar, Traditional Grammar, Structural Grammar

It is totally agreed by nearly all linguists and languages' specialists that any language must have a grammar. Yet and most importantly, it is partially agreed and seemly impossible for those linguists to decide what does this grammar consist of or what its component are. As long as the human beings, that is, nearly from the time of Greek and Roman philosophers till now, many types (approaches) of grammar have appeared. Of course, some of these grammars if not many, especially old (ancient) ones, are no more alive. Put it differently, they are only used as data of comparative linguistic studies to present the types of grammars. Otherwise, they are considered for one or more reasons as traditional, useless, incomprehensive, illogical, etc.

Has it been agreeable that any language must have grammar; it is disagreeable what kind of grammar is it? Put it another way, linguists and other specialists who are interested in languages but mainly grammarians have argued on the idea that on what bases they have to describe/study a language, namely its grammar? As far as the researcher is concerned, it is a matter of proving what is adequate or inadequate or which from which is capable of raising a number of the

\footnotetext{
${ }^{1}$ Department of Linguistics, Social Sciences Institute, Ankara University, 06100, Sihhiye, Ankara, Turkey *Corresponding Author

(c) 2015 I A Alduais; licensee IJIP. This is an Open Access Research distributed under the terms of the Creative Commons Attribution License (http://creativecommons.org/licenses/by/2.0), which permits unrestricted use, distribution, and reproduction in any Medium, provided the original work is properly cited.
} 


\section{An Account of Rise and Fall of Transformational Generative Grammar TGG: A Descriptive Study}

questions and providing and proving their answers, yet, is ready to answer others' questions. Such a point, however, is used as a war-tool or war-weapon among proponents of nearly all grammar types. That is to say, it is because some particular studies have proved that such a particular approach is better than another for a number of reasons which will be later the basic principle of a new type of grammar. Certainly, it is not necessary that this new type of grammar or theory will be a total alternative to the previous one, but it becomes more confidential than the other.

Strictly speaking, the question here is why do we have more than one type of grammar? Or descriptively, why do we have traditional grammar, structural, descriptive, prescriptive, functional, functional unification grammar, case grammar, categorial, lexical-functional grammar, Montague, port-Royal, scale and category, systemic grammar, and generative transformational grammar? It seems that an abstract thing is discussed by an abstract thing.

For it is not our concern here to decide why all these types and some other types of grammar have evolved, we can raise another question which is really our concern in this paper. The question is why traditional grammar, for instance, is more capable or adequate than the case grammar, or vice versa? Thus, in this term paper, the researcher will critically present one type of these grammars which is Transformational Generative Grammar (TGG). The raised question here is that why do TGG has risen and at the same time why it is falling? Basically, the researcher will briefly present transformational generative grammar and then how it has risen above other grammars and proved as an adequate approach. Having finished that, the researcher will then move to the opposite point: why transformational generative grammar is falling? As usual, the paper will be concluded stating precisely all nature of transformational generative grammar, its rise and its fall.

\section{BACKGROUND}

Principally, proponents of any new grammatical approach or type claim that such previous approach is inadequate and insufficient to interpret/investigate or study the grammar of language. Since the early studies of language, at the level of the world, traditional grammar which was mainly established by Greek and Roman grammarians and philosophers, was the dominant type or may be the only one available at that time. In spite of this, the time has come to change, many linguists particularly those who were likely unsatisfied with following the Greek and Roman traditional methods, have made attempts trying to make clear the faults and disadvantages of the traditional approach. Needless to say, Greek and Latin grammarians have established most of the basic concepts of grammar and their contributions to grammar of language cannot be denied or ignored. Dinneen, in Malmkjær (2006:p.643) states that one of the most virtues or values of traditional grammar is that it was "the most wide-spread, influential, and best understood method of discussing Indo-European languages in the Western world”. On the contrary, for other linguists such as Palmer and Chomsky it is "unintelligible to most people though they may have 
some dim recollection of them from their schoolboys", (ibid). The same is in the case of Chomsky who believes it "based largely on intuitions about grammatical meaning”, (ibid).

As result of these conducted studies and hypotheses which were raised against traditional grammar, it fell and instead other types of grammar have risen and became the concern or the subjects of study mainly from the end of the 18th century and onward. Among these grammars and which was greatly influenced by the Greek and Latin grammars is an approach called prescriptive grammar. Proponents of this approach believe that "it is one thing to adopt the grammatical labels (e.g. 'noun, 'verb') to categorize words in English sentences; it is quite another thing to go on to claim the structure of English should be like the structure of sentences in Latin”. They thought that language rules should be determined and identified so that any one must follow them to learn and acquire any particular language. Claiming that such an approach can be useful for some languages but not for English and some other languages, a number of the linguists have established what is known now as descriptive grammar. They believe that the grammar of language should be described but not identified. They opposed the idea that people must be obliged to follow rules of grammar, instead they argue in favor of that what people say is what should be taught and taken as the grammar of language.

Having briefly mentioned some points about some types of grammar and how it happens for an approach to rise and fall, now we move to our main topic hear which is presenting or introducing TGG. Who established it? When it has started? How is it defined by other linguists and specialists? What does it say about language and its grammar? All these questions will be briefly answered in this section.

Primarily, it is called Transformational Grammar (TG) and more "fully” as Transformational Generative Grammar (TGG), (Trask, 1992: p. 282). Basically, two words or more accurately terms of this name which are 'transformational' and 'generative' are quoted from mathematical theories to refer to some linguistic principles applied to grammar. Crystal (1997:p.166) states that 'generative' is "a term derived from mathematics, and introduced by Noam Chomsky, in his Syntactic Structures (1957), to refer to the capacity of a GRAMMAR to define ... the set of grammatical SENTENCES in a language”. Such a thing is also proved by (Wales, 2001: p. 174) who states that "the term generative was first introduced by Chomsky (1957) to describe a specific group of GRAMMARS which explicitly aim by a set of finite rules to describe and produce (generate) all and only the Grammatical Sentences of a language”. Chomsky who is considered the father of this approach has chosen such terms because he was previously a student of mathematics.

Trask (ibid: p.282) defines TGG as "a theory of grammar conceived by Noam Chomsky in the 1950s and elaborated by Chomsky and others during the succeeding decades”. He continues, TGG is "a grammar for a particular language which at least enumerates and usually also characterizes (assigns structures to) all and only the well-formed sentences of that language”, 
(ibid: p.117). Trask believes that "such a grammar differs from other approaches to grammatical description in that it is fully explicit, leaving nothing to be filled in by a human reader', (ibid: p. 117).

In the same way, Ambrose (1978:p. 50) defines TGG as "a grammar able to describe a language and establish rules which account for the potential utterances of that particular language”.

Crystal (ibid: p. 166) declares that technically "a generative grammar is a set of FORMAL RULES which PROJECTS a finite set of sentences upon the potentiality infinite set of sentences that constitute the language as a whole, and it does this in an explicit manner, ASSIGNING to each a set of STRUCTURAL DESCRIPTIONS”. Unlike the above mentioned definitions Byram (2004: p. 232-3) attempts to present historically the notion of TGG rather than the approach itself, he even mentioned it as 'generative principle' rather than generative grammar. He states "the generative principle refers to the human ability to generate an infinite number of sentences from a finite grammatical COMPETENCE". He clarifies this pointing that "it" he means this human ability “... reflects the crucial feature of human language sometimes called compositionality, meanings are built out of parts and from the way they are combined”. He mentions Palmer and Humboldt as originators of this principle before Chomsky. Needless to say, it is not necessary that Chomsky was the first introducing this term but it is a truth that cannot be denied that he (CHOMSKY) is the one who has brought this theory to life.

Again, Richards (1992: p.386-7,154-5) but in a fuller and more comprehensive way attempts to bring to us all different names of this type of grammar. He declares clearly whether we say transformational grammar, transformational generative grammar, generative transformational grammar, generative grammar or generative transformational theory-all are referring to the same approach. He defines such an approach or theory; however, by that "a theory of grammar which was proposed by the American linguist Chomsky in 1957...has been developed by him and many other linguists” which by, he, means Chomsky “...attempted to provide a model for the description of all languages”, (ibid: p.387).

In general statements, Johnson (1998: pp. 138-140) makes an attempt to generally define or identify what and which types of grammar can be mentioned as generative and on other hand what and which cannot be mentioned as generative grammar. He starts by mentioning that “ the term generative means that the grammar is formal and explicit; when we speak of the linguist's grammar as a generative grammar we mean only that is sufficiently explicit to determine how sentences of the language are in fact characterized by the grammar". He goes on " this approach, pioneered by Chomsky in 1957, made the form of the rules explicit so that nothing needed to be read into them”, (Johnson, ibid: p.138). Furthermore, Johnson suggests and of course from the point of view of Chomsky's ideas "in principle there is no way of doing generative grammar; any grammar is generative if its form of statement is sufficiently explicit”, (ibid: p. 139). Like Johnson(ibid) is Wales (ibid) who believes that TGG is the one which is 


\section{An Account of Rise and Fall of Transformational Generative Grammar TGG: A Descriptive Study}

"variously known as transformational grammar, transformational generative grammar and GENERATIVE GRAMMAR, this influential grammatical theory and model is particularly associated with the work of Chomsky from the late 1950s and 1960s onwards”, (Wales, ibid: p. 395).

Unlike the above mentioned definitions is Trask's one (2007: pp 101-3, 319-21) who introduces TGG in terms of its features and principles. Needless to say, such an author has been mentioned above and he defines TGG in a way which is similar to other mentioned authors, but her it is partially different. He maintains "the notion of generative grammar was introduced by Noam Chomsky in 1950", such a type of grammar he mentions as "mechanical and mindless" and "a successful generative grammar must have the property of recursion: a single rule must be allowed to apply over and over in the construction of a single sentence”. He continues (ibid: p. 102), "a key characteristic of any generative grammar is its power, the larger the number of different kinds of grammatical phenomena the grammar can handle successfully, the more powerful is the grammar”. Trask believes that Chomsky's TGG is not the only one for there are other generative types but and according to Trask Chomsky is the one who initiated such an idea. He declares (2007: p. 319), "transformational grammar is a type of generative grammar" introduced by Noam Chomsky, but now "there are very many different types of generative grammar which can be conceived of". He then returns to say "most types of generative grammar in which anybody has ever been interested can be usefully viewed as working like this: starting with nothing, the rules of grammar build up the structure of a sentence piece by piece, adding some thing at each step, until the sentence structure is complete”. He concludes (ibid: p. 320) "TGG thus is a theory of grammar which holds that a sentence typically has more than one level of structure" and it "has developed through a number of versions each succeeding the other". Add to what have been mentioned above, Malmkjær’s definition (2006: p. 218) who maintains:

A generative grammar of some language is the set of rules that defines the unlimited number of sentences of the language and associates each with an appropriate grammatical description, the concept is usually associated with linguistic models that have a mathematical structure and with a particular view of the abstract nature of linguistic theory through the early work of Noam Chomsky and perhaps for this reason is often, though wrongly, associated exclusively with his school of linguistics.

Continuing to describe this type of grammar, Malmkjær (ibid: p.219) suggests

Simple though this grammar is, it is formulated in accordance with some general principles... the most general of these is that a grammar consists of a number of distinct components; in this case there are two: a syntax, which defines permissible constituent structures, and a lexicon, which lists the words in the language and the lexical class to which each belongs. 
Obviously, the majority of the above mentioned definitions and statements if not all state or prove that there is an approach of grammar namely TGG and it had been pioneered by the American linguist Noam Chomsky. Not surprisingly to say that whenever this type of grammar is mentioned Chomsky is and [must be] mentioned as he is the one who has been and is being mainly and directly responsible for both establishing and developing this type of grammar.

To sum up, we came to know through all these mentioned definitions that this type of grammar has been greatly influenced by mathematics and it succeeded by its proponents lead by Chomsky to approach language and its grammar innovatively. Yet, grammar is introduced in a way that proves the spots of weakness in the previous approaches such as traditional and structural grammars. This idea, that is, how TGG has risen, will be the main idea of the 3rd section in this term paper.

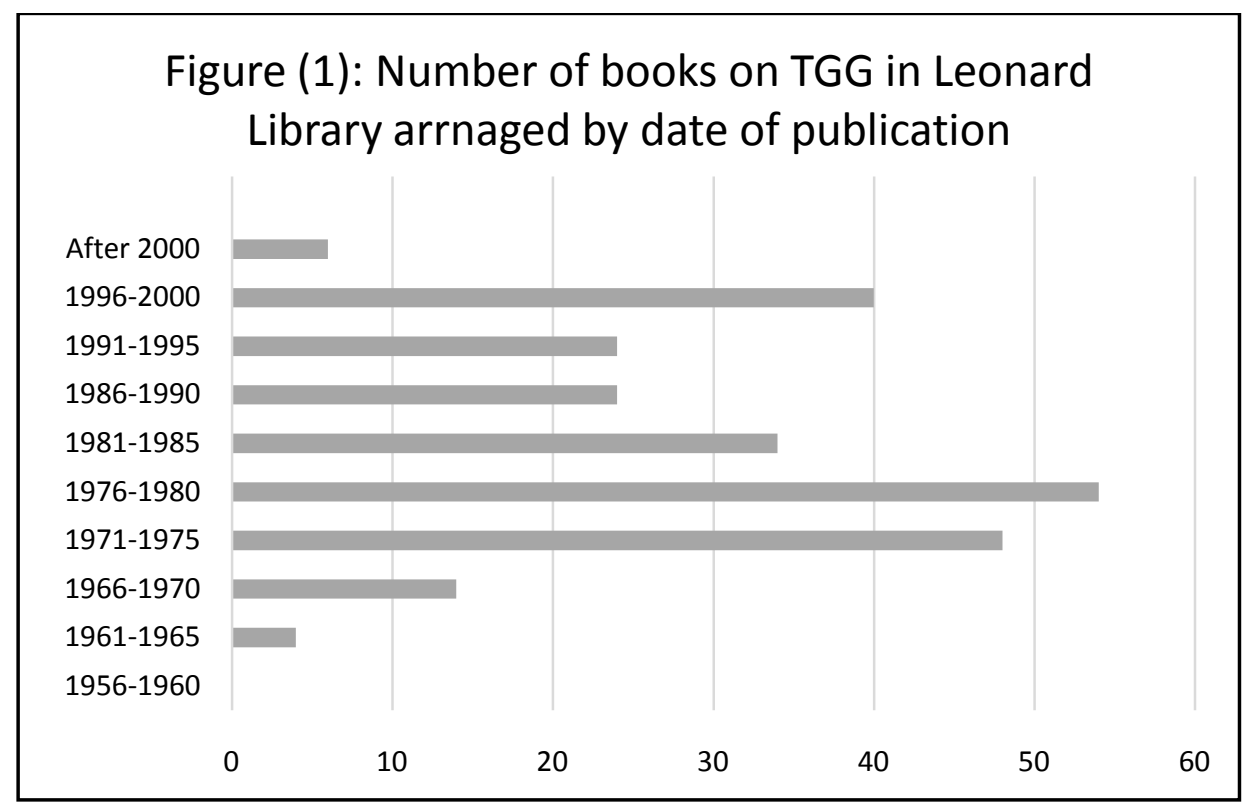

The above histogram is taken form one of the websites and it shows estimations of the published and composed books on TGG. Though these numbers are limited to only one library, they can help us understand and realize how this type of grammar has risen and at the same time how it has fallen. It is clear that the number of the books increased gradually from the mid-1950s onwards. A considerable increasing in the number of the books is between the early-1970 and late-1980s. It marks actually the rise of this approach. After that, we can notice how it dramatically started to decrease or become less step by step. The number of the books decreases to less than ten from 2000 and onwards. 


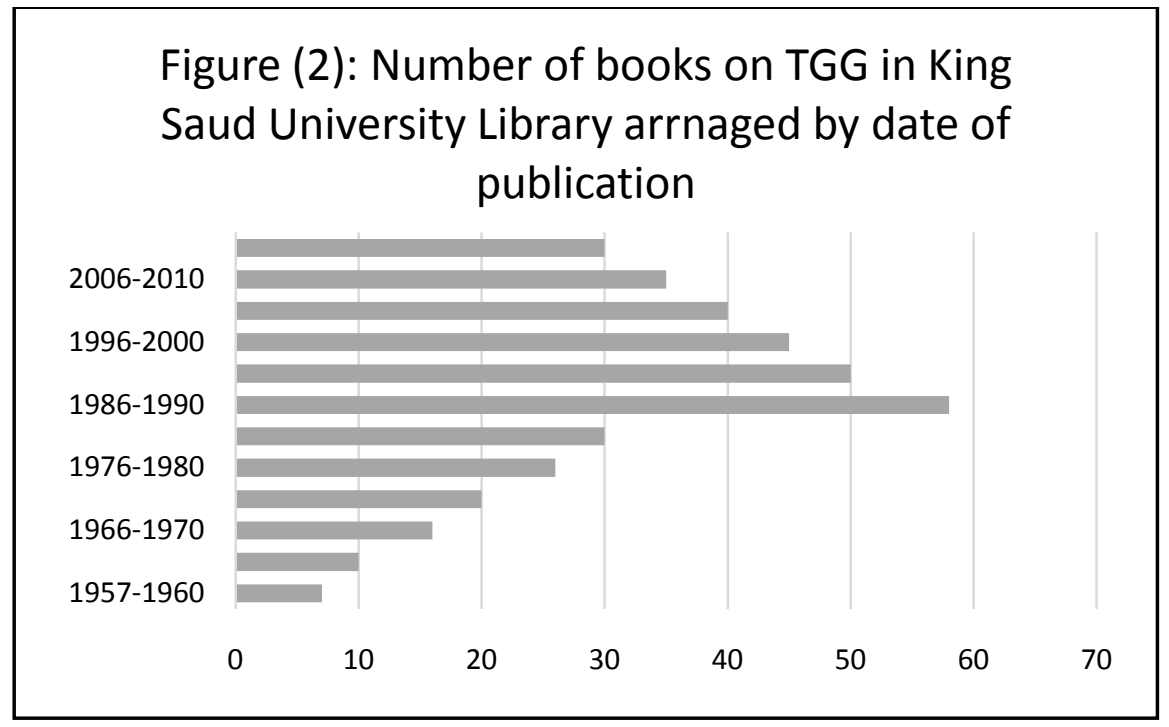

Similar to the histogram (1) the researcher made an attempt to made one in the Libraries of King Saud University. The researcher based wholly on the number of the books available in the library and which clearly discuss transformational generative grammar whether in favor or against. This histogram (2), however, clarifies how even in the libraries one can feel the rise and the fall of such an approach through the number of the available books and mainly their dates of publication. It is clear here that there is a gradual increase in the number of the books from 1957 to 1980 . After the late-1980s the number of the books starts to decrease to the extent it reaches to less than more ten books, especially in the period from 2005 to 2009.

Figure (3): Establishment, rise and fall of TGG in years

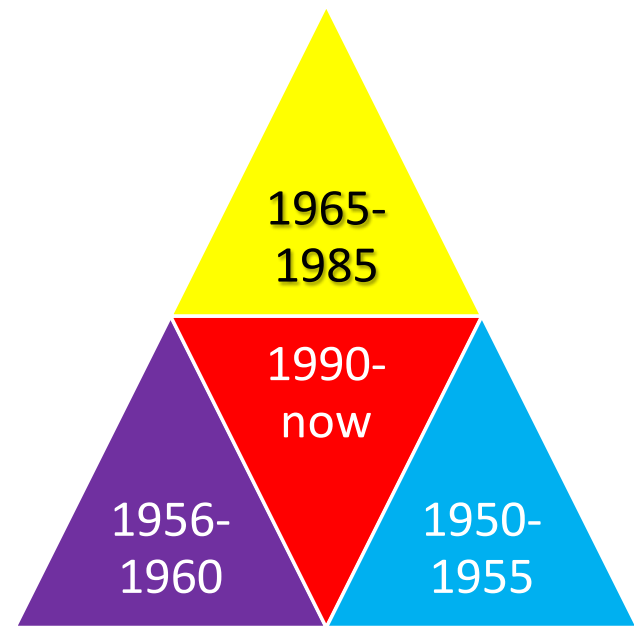

This graph illustrates three main points regarding the TGG. Boxes colored with light blue show the period of establishing this approach, boxes colored with red show the period of the rise of this approach and finally boxes with light green color show the period of the fall of this approach. Yet, such dates are not to be considered as final statements because during the period 
of establishing this approach or theory and during the period of the rise of this approach as well, there were many objections against this type of grammar. That is, they were rejected by Chomsky as a reply to these objections especially by his modifications to his theory. But and later on, when this approach was no more able to bring modifications and answer some unanswerable questions it started to fall one decade after another.

Figure (4): TGG from heydays to critical days

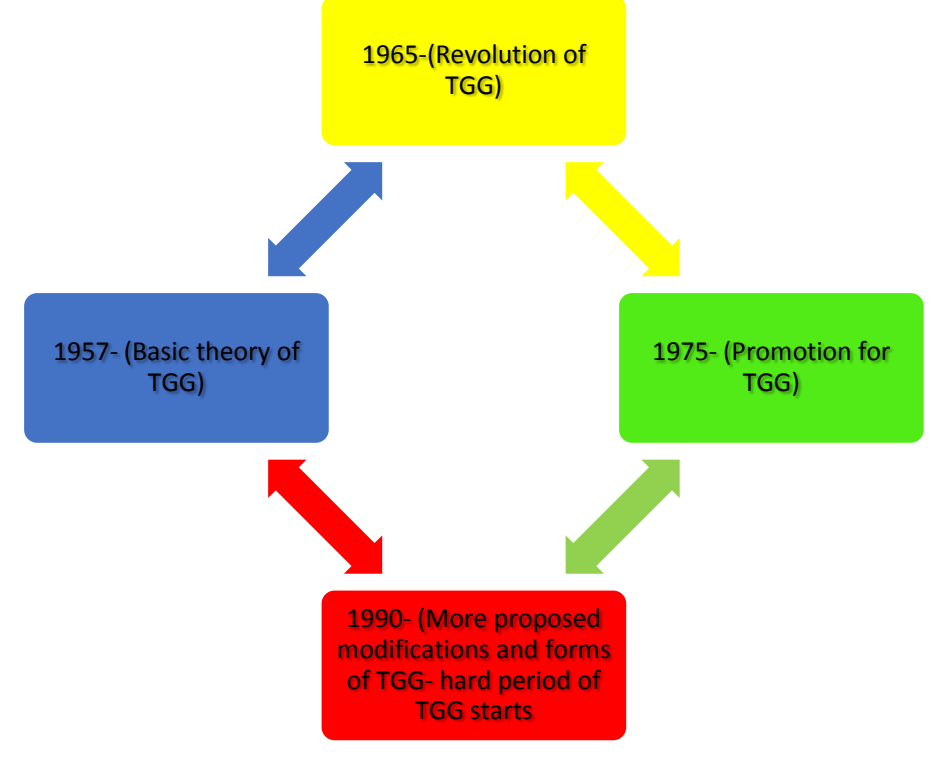

This pie chart is designed as an attempt to illustrate two contradictive ideas regarding TGG. That is to say, the establishment of the this approach along with rise and at the same time indicating how nearly all the published books and conducted studies about TGG starting from about 1960 to 1990 or less are in favor of this approach. Or instead, they all promote for TGG. On the contrary, the majority of the books, journals, conducted researches and studies coming after 1990 are criticizing this type of grammar. More importantly, from the beginning of the 21st century, the criticism has become more directed; a person can hardly find some statements which praise such an approach. Needless to say, none of these authors can deny the benefits and the advantages of this approach, but they believe it is no more powerful

\section{Rise of Transformational Generative Grammar (TGG)}

Having introduced some basic ideas about the nature of TGG, the researcher, now will discuss why this type of grammar has risen? Above all, how it operates on language and what makes it rise above other grammars?

Strictly speaking, it is widely admitted by all specialists in general that whatever theory it is, in whatever field it is, is applicable to both to be proved or disapproved according to its ability to interpret and answer any enquiries about the science it raises. Similar to this are types of grammar or approaches; a particular type of grammar my reach to the top in particular times and then will dramatically fall. That is, the more faults and spots of weakness appear, the more it 
falls. On the opposite, the less faults and problems it has, the more it rises. In other words, the more powerful it is, the more adequate and capable to solve language problems and introduce them in a simpler way and more explicit, the less probabilities of its collapse.

One more important thing is that none can claim or may be will dare to make a claim that a particular theory or approach of language and grammar is the first and the last, or it should be the dominant one forever. Such a truth, however, cannot be denied because language itself is abstract and whatever claims have been made about it are only predictions and speculations. Of course, some have proved true but who knows, may a day will come and the true becomes untrue! LaPalombara (1976: p. xi) introduces his book by warning his readers:

The reader should understand that the 'correct' approach to grammar study and the proper philosophy about human nature and human use of language have never been and probably never will be established for all time. No one approach has remained entirely unquestioned, even in its heyday.

He, LaPalombara, states that the beginning of criticizing traditional grammar started by some objections, were raised by Priestly who was a scientist and grammarian, and by the American lexicographer Noah Webster. Then, the problem extended when a new approach called descriptive approach came into life and it was actually as a protest to the traditional prescriptive grammar.

In the meantime, some other linguists who were unhappy with traditionalists' ideas, were preparing the basic principles of a new approach, they called later structural grammar instead of traditional grammar, (ibid: p. 97). Unsatisfied with what the structuralists have done LaPalombara (ibid: p. 97) states

Most of the structuralists has become extremely critical of traditional grammarians... in any case, most of the structuralists expressed the utmost contempt for the methods of traditional grammarians, most of which they labeled 'misguided'... they attacked traditional grammar as meaning-dependent, subjective, prescriptive, intuitive- in short, as insufficient.

Being lead by Franz Boas, then Edward Sapir and later on Bloomfield, structuralism had risen and the more it was rising the more the traditional approach was falling and becoming less important. Objectively, but not subjectively, as in the case of traditionalists or prescriptivists, structuralists have derived their way to describe language, (ibid: p. 98). Unfortunately, this approach didn't long too much, "for nearly three decades" as LaPalombara (ibid: p. 103) indicates. At that time, Chomsky whose new approach- TGG is our concern here, has launched his grammatical project. Like any other linguists or theorists, Chomsky has started this project by critical studies for nearly all the previous types of grammar. Certainly, he wanted to be sure that 
what he is going to do is something innovative, a thing that has been never discussed or presented in a way similar to his.

Consequently, Chomsky first rejected the ideas of traditionalists claiming that their approach is inadequate. Then he turns to structuralists whom, he maintains had built their theory "upon 'wrong' assumption to the rejection of such specific structuralists' methods as their taxonomic date-gathering techniques and their belief in the adequacy of 'discovery procedures', "LaPalombara, ibid: p. 209).

Needless to say, there are a number of reasons behind the rise of TGG which the researcher actually will provide and discuss now. Firstly, for Chomsky "the first problem in developing a correct theory (grammar) is that of selecting criteria", and the criteria which was chosen by him is no doubt more powerful than other approaches criteria. Malmkjær (2006: p.648) proves such an idea claiming that "in the mid-1960s work on the developing theory of transformational grammar (TG) was perhaps coherent for one to be able to talk of a school of transformational linguistics”.

Secondly, the influence of generative transformational approach on some different and various fields which by, their proponents want to apply such an approach on their interests such as "generative poetics", "generative grammar on metrics", " generative grammar on stylistics", "generative phonology" and "generative semantics", (Wales, ibid: pp. 174-5). Johnson (1998: p. 138) believes that TGG has risen because its innovativeness ideas and principles, he declares:

Hence generative grammars contrasts with traditional grammars, which left many rules of the grammar to the interpretation of the reader; such grammars dealt primarily with the idiosyncratic forms that were not 'obvious' and thus left it to the reader to know what a 'noun' was or what the basic word order of the sentence was. A generative grammar therefore tried to specify everything that is necessary on the printed page rather than leaving it to the imagination.

Agreeing with the previous opinions as reason for the rise of TGG, Crystal (1997: p. 394) proposes that "the arguments" he means the arguments provided by Chomsky and his followers "... were persuasive, and as a result transformational grammars became the most influential type in the development of generative grammatical theory”.

Have risen and become studied and spread worldwide, many linguists thought that it is this type of grammar or theory which will solve all unsolved problems regarding language, or in other words, will answer all unanswered questions. Brown (1984: p. 148) states:

... standard theory provoked a great flurry of research in the late 1960s and early 1970s, and the prospects opened up by this powerful new tool seemed to offer the 


\section{An Account of Rise and Fall of Transformational Generative Grammar TGG: A Descriptive Study}

hope that vigorous research into the syntax of English and other languages might force a particular language, and perhaps language in general, to yield up its secrets

Moreover, TGG has been discussed and applied to languages worldwide. Among these languages is the Arabic language. Al-Khuli (1979) conducted a research attempting to apply these rules and principles on the standard Arabic language. He states "the aim of this study is devising a transformational grammar for Arabic and then finding out where Arabic and English are different and where they are similar”, (ibid: p.1). Al-Khuli turns his choice for this type of grammar for a number of reasons which, he believes makes it distinguished from other grammars such as traditional and structural grammars, (ibid: pp6-7). Therefore, it is worthy to mention some of these reasons as they are really reasons for the rise of this type of grammar.

The T-grammar does not look at the sentences as simply made up of various constituents. It views it as derived from another underlying structure through a transformational process. This view is informative about the nature of language.

The T-grammar accounts for the speaker's ability to produce and understand an indefinite number of new sentences, sentences that he hears or produces for the first time. It accounts efficiently for complex sentences that are accounted for clumsily by other grammars.

These features and other features have made Al-Khuli chose this type rather than other types of grammar. In spite of this, he turns to say, "This does not mean that other grammars, i.e., nontransformational ones, don't account for any of the previously-mentioned matters. What is meant is that T-grammar accounts in a more efficient, systematic and explicit way”, (ibid: pp. 7-8). He goes on to illustrate the main reasons of the rise of this approach and at the same time why he did choose it "it does it in a mathematical way: the given, the process, and the result". He illustrates and at the same time attempts to draw some distinctions between TGG and other grammars, mainly here the traditional grammar:

The $\mathrm{S}$ is different from the sentence in traditional grammar, which gives the sentence a definition that can indicate anything from a single word to a volume. $\mathrm{S}$ here is 'a designation for a unit which is basic to grammatical patterns as described by a transformational grammar. It is what the grammar itself defines and covers.

Later on, Al-Khuli might try to convince us that each type of grammar can suit some particular purposes which another type cannot suit for. For instance, TGG is not suitable for pedagogical purposes but traditional grammar is. Once again, Al-Khuli proposes within TGG itself, we can have many types of grammar. It seems he believes that a TGG in Arabic language, for example,

is different from TGG in English and the same case in the French or German languages. To a great extent, what he has mentioned is may be true but other linguists as we will show later on, 
will argue that TGG can be used for pedagogical purposes and can prove more positive and educational results than traditional and structural grammars. Al-Khuli made use of Fillmore's model of the base and he concluded that "the base can efficiently meet the requirements of the deep structures of Arabic sentences, or, more precisely, of those sentences in the corpus", (ibid: p106). He proves that "limited degree of similarity between" Arabic and English in the surface structures level, and "a remarkable sameness between the two languages" at the level of deep structures, (ibid: p106).in their book, Atkinson, Kilby and Roca (1982) present more than one type of grammar and they mentioned that transformational approach was able to approach and consider insights in language which the previous approaches were not able to approach. They believe that such a thing is one of the main reasons for the rise of such an approach and for being the dominant for more than 40 years, (ibid: p. 165).

For Bierwisch (1971: p. 45-62), TGG has risen because its proponents mainly their leader Chomsky was able to classify and at the time unify nearly all that have been said about language and then he mixed it with his new ideas in relation to mathematical logic and psychology. Such a feature, Bierwisch believes is a major reason for the rise of this approach. He declares (ibid: p. 45):

It was an extract of the results of extensive theoretical research into the foundations and the structure of linguistics. Although it originated in America and grew out of a critical discussion of the ideas of Harris, the theory it presents incorporates the most important ideas of Saussure, Sapir, Trubetzkoy, and Jakobson, combining them with recent insights in the fields of mathematical logic and psychology.

Moreover, he turns the success of this theory for its motto or principles. He attempts to summarise the main ideas of this theory stating that "whoever speaks a natural language does not simply carry around in his head a long list of words or sentences which he has stored, but is able to form new sentences and to understand utterances he has never heard before”, (ibid: 45).

Add to the above mentioned reasons for the rise of TGG, Anttila (1977) who in favor of such an approach believes that it effects positively many trends in linguistics mainly historical linguistics. He adds that it arose; he means TGG, many questions about the previous trends in linguistics such as those investigated by traditionalists and structuralists and it was able to bring more logical answers than those brought by others. Dissimilar to this opinion but it also explains the rise of this type of grammar in particular and all modern types of grammar in general is Lehmann's (1972: p.35) view who points out:

If language is to be understood as a phenomenon, the components of language must be dealt with as parts of a whole. In the past such understanding of language was attempted indirectly, for the procedures available were inadequate to deal with the complexities of communication systems, only recently have adequate 
procedures been devised by mathematicians and symbolic logicians as well as linguists. The procedures employed today in the description of language are increasingly formal, and the statements regarding language often resemble mathematical formulas.

Additionally, Thakur (2001) in his book Syntax, starts from traditional to structural, to transformational and then to case grammar. At last, it seems in his book that TGG has proved the most adequate type of grammars. Certainly, he also mentions its fall but this will be discussed later in the coming section. What is important here, however, is that TGG has risen because of its continuous developments and modifications from the point of view of Thakur.

Starting his book by stating the job of a linguist or whatever specialist in the field of language, Baker (1978: p. 5) believes:

If a speaker's unconscious system of rules cannot be discovered by direct questioning, what alternative approach is available? The approach that has been most widely adopted throughout the history of linguistic studies is to try to infer something about the unconscious rules of a language by studying the conscious judgments in which the rules are manifested. What a linguist attempts to do is to formulate explicitly a set of rules which mirror the effects of the native speaker's unconscious system rules. Such a set of rules is frequently referred to as a grammar.

Later on, he declares that TGG is to a great extent the most suitable approach doing such a job and applying such a method, yet achieving this aim.

Typically, it seems that TGG was approved by many linguists and authors and specialists worldwide. That is to say, the large numbers of the conducted studies and books discussing and presenting this approach have greatly helped to spread this approach and make it rise over other grammars. For instance, consider Allen’s and Van Buren (1971: preface) book who state:

Chomsky's approach to linguistic description became widely known as a result of the publication of Syntactic Structures in 1957. In the twelve years that have elapsed since then, transformational-generative grammar- 'TG' for short- has established itself as one of the most vigorous and exciting movements in modern linguistics, and one which many people believe has far-reaching implications for the study of human cognitive processes.

More interestingly is the debate between Chomsky and Piaget, where in we can infer some reasons for the rise of Chomsky's approach, (Piattelli-Palmarini, 1980). Chomsky appears in this debate as more logical and his ideas seem from the point of view of some critics more 
reasonable. He admits during this debate and as a reply to one of the questions directed to him regarding his theory, "these are all hypotheses... I will repeat again that they are conjectures, scientific hypotheses, and if you want to know my feeling, I'm sure that they are false. I cannot believe that any detailed hypothesis that I can propose today, or that anybody else can propose, is likely to be sure”, (ibid: pp. 273-4).

Like some of the above mentioned reasons, Helbig (2007) turns what he called the constant developments and modifications as marks of success and rise of this type of grammar. Yet, he later on, declares that such modifications lead to many generative transformationalists and to many rejections and objections against this approach.

Unlike Helbig, Collinge (1990) shows Chomsky as a linguist who has changed the science of linguistics mainly its grammar from worse to better. He brings as many reasons as possible proving that Chomsky's theory of TGG has lead the world of linguistics to great development.

Above all, no doubt Chomsky's books are actually continuous developments for his theory rather than books in linguistics. That is, starting form Syntactic Structures in 1957 where in this theory was founded and its basic principles and notions were announced. It was a remark of a new revolution in the field of linguistics. The next book Aspects of the Theory of Syntax in 1965 came as a modifier for this theory, because Chomsky and other proponents of this approach realized that the previous model was incapable of describing the whole processes of grammar and it proves insufficient and inadequate. For that matter, this book has appeared with some modification. A noticeable point of modification in this book is the rule that all sentences had deep structures which were mainly transformed into surface structures.

After that Chomsky's book Lectures on Government and Binding Theory (1981) was presented. In this book, Chomsky expands the network of his approach starting with English, moving to Romance languages, then to Japanese and to Arabic language. Recently, he published The Minimalist Program (1989, 1992, 1994), where in, he establishes more general properties for describing the grammar of language such as principle of economy. Some would disagree to the idea that his last two works are not related to the theory of TGG claiming that they are to a great extent different from the first theory proposed in the Syntactic Structures and modified in the Aspects of the Theory of Syntax.

Nevertheless, whatever they were, they greatly contribute to the development and mainly to the rise of this theory of TGG. That is, all- standard theory (ST), extended standard theory (EST) 
and then revised extended standard theory (REST) are completing and modifying each other and have caused for the rise of this type of grammar.

In the following pages and as a conclusion of this section, the researcher provides some illustrations to show the basic changes in the modifications of the theory of TGG. Needless to say, the purpose of doing so is to clarify how these modifications took part in the rise of this approach and acted as energy sources for empowering such an approach.

Figure (5): Development of TGG

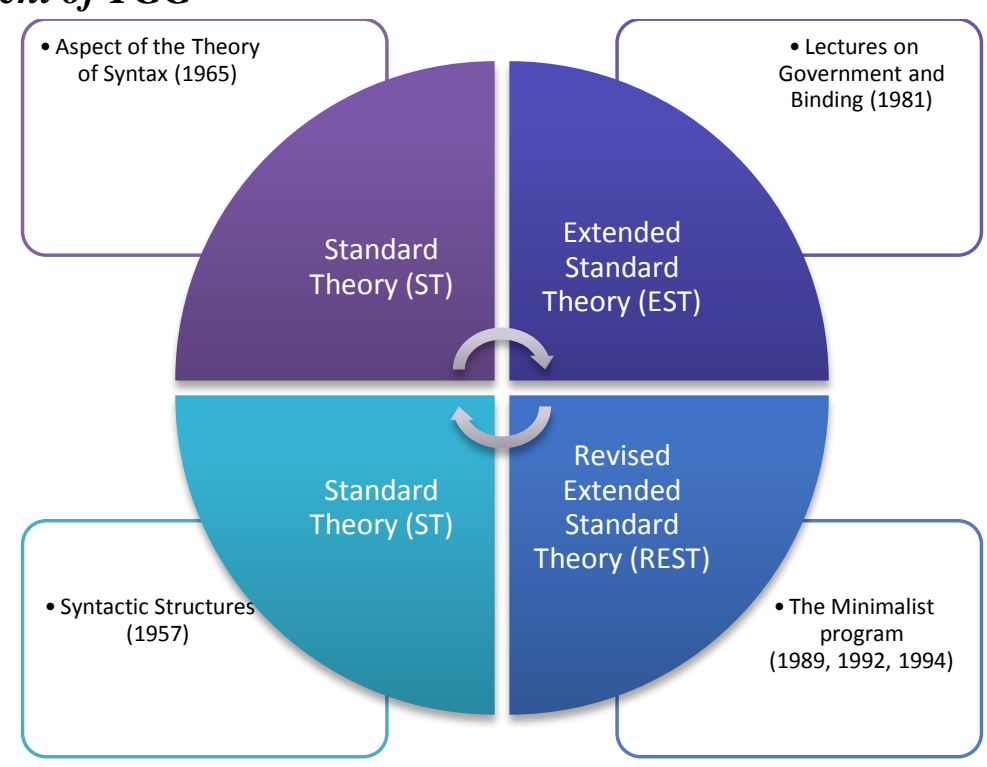


Figure (6): TGG's component base

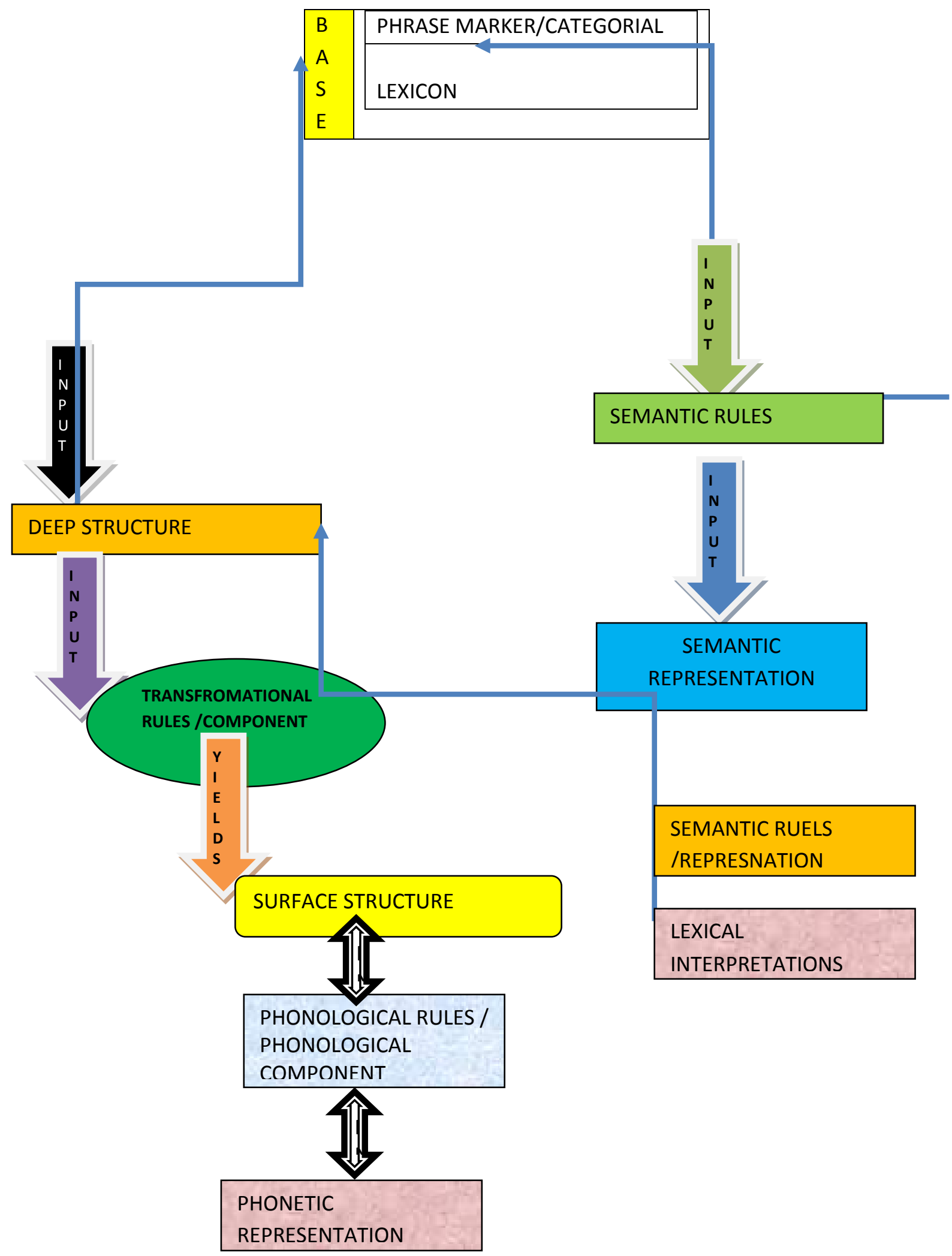


Figure (7): Recent TGG's component base

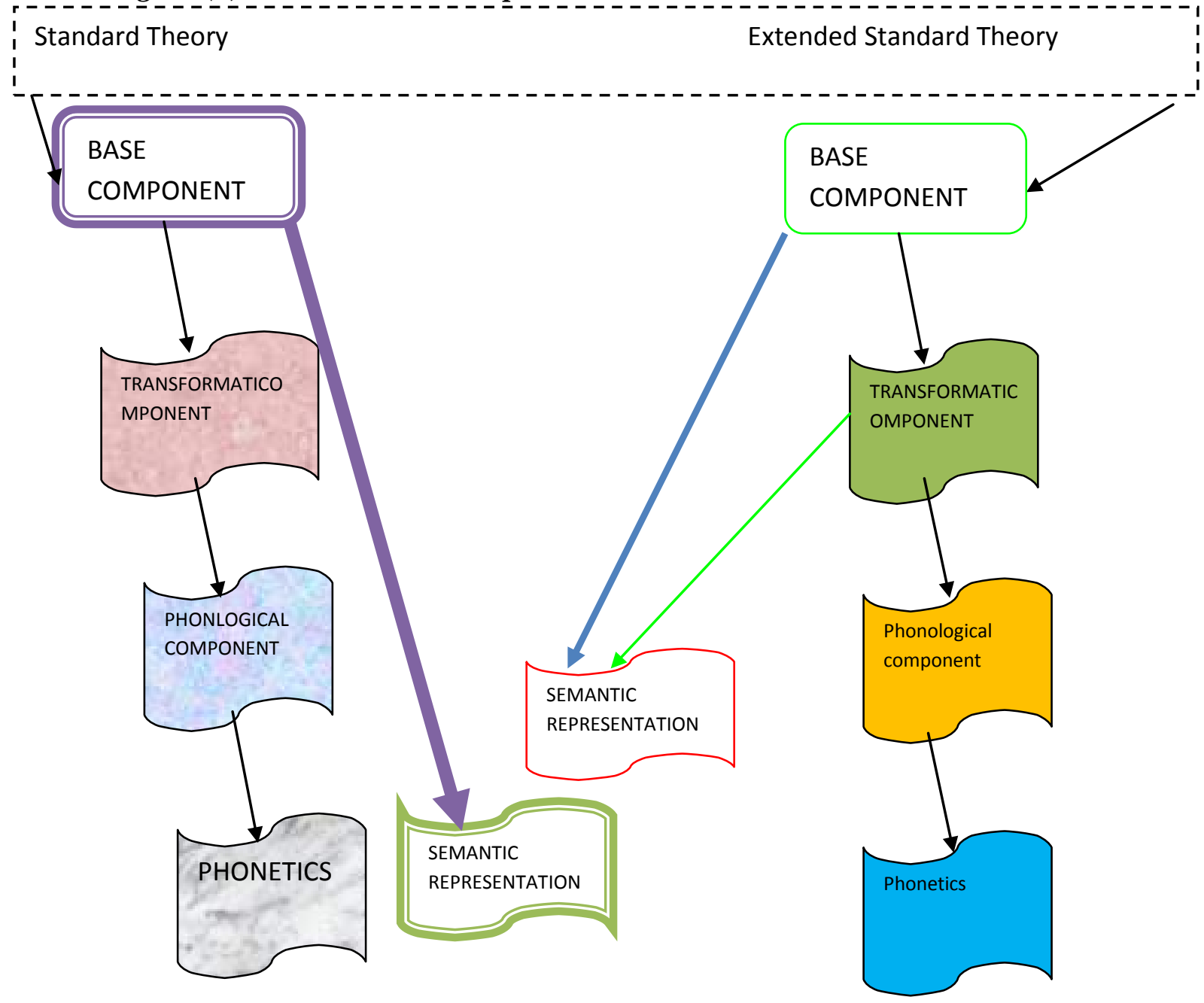

Having discussed and introduced the main reason of the rise TGG, in the next section, the researcher will briefly discuss the opposite idea which is the FALL of this type of grammar. But it is important to note the importance of relating the provided date in the previous sections in form of charts to both the rise and fall of this approach.

\section{Fall of Transformational Generative Grammar (TGG)}

As a matter of fact, since the early days of founding the TGG, it was criticized. Some of the linguists at that time (1960s) mainly structuralists were unsatisfied with Chomsky's ideas. Some others consider Chomsky's model of grammar as mathematics-like and as very complex and incomprehensible. Others claim that being developed and modified many times, so it is no more to be called TGG. They justify their opinion by saying that Chomsky's last or recent modifications namely the government and binding theory and the minimalist program are very much different from the earlier programs. One more claim against this approach and which is actually very influential is that one stated and raised by generative semanticists. They think that 
Chomsky has concentrated very much on syntax and neglected the meaning which greatly contributes and acts juts as effectively as the syntax. Thus, all these claims/reasons have contributed to the fall of this type of grammar.

The claim that developing and modifying the TGG theory mainly the final modifications mentioned in Chomsky's two final books: Lectures on Government and Binding and The Minimalist Program is worthy to begin with. Trask (2007: p. 321) points out that these two books or programs in particular are directly related to the earlier ones. By the earlier one he means Syntactic Structures and Aspect of the Theory of Syntax. With reference to this point, Trask states "...for the purpose of linguistic research, transformational grammar may now be regarded as dead, though its influence has been enormous, and its successors are maximally prominent", (ibid: p. 321). It indicates that such an approach has risen and is gradually falling.

Moving to another point is that some of the opposing schools of grammar to the TGG. From among these schools is lexical functional grammar (LFG) and generalized phrase structure grammars (GPSG) who criticize Chomsky's approach for focusing on the sentence rather than words and things beyond the level of the sentence. For instance, Gazdar in Johnson (1998: p. 140) "attacked current Chomskyan grammar for not being generative since principles and parameters are not as explicit and clearly testable as the earlier rewrite 'rules' and transformations". Similarly, (GPSG) "rejects transformational rules, claiming that phrase structure rules are perfectly adequate when expanded in various ways", (ibid).

One more spot of weakness which has been proved in this approach is that it cannot be applied in text linguistics level. Crystal (1997: p. 395) maintains "the transformational-generative model was also used and applied in TEXT LINGUISTICS from the 1970s... Chomsky's model was soon proved inadequate as a means for generating a whole text, since the theory is essentially sentence-based".

Add to the above mentioned reasons the point that from within the basic TGG approach, other types have diverged and considered themselves as transformation lists. This divergence, however, and being divided into small schools each one rejecting the others' ideas for some point of disagreement among them has greatly but negatively contributed in the fall of this type of grammar. Malmkjær (2006: p. 648) declares that the truth to say that the TGG approach is the most influential and valid among the other approaches of grammar "is not possible today... many who grew up within the model have gone on to develop theories of their own, often in reaction to the current work of Chomsky, and even among those who would describe themselves as transformational linguists there is considerable divergence”.

In addition, the argument which arose between Chomsky and generative semanticists about the representation of the deep structures in semantics is one of the reasons which contributed partially in the fall of this approach. Thakur (2001: p. 193) states: 


\section{An Account of Rise and Fall of Transformational Generative Grammar TGG: A Descriptive Study}

A year or two after the publication of the Aspects, a number of linguists working within the framework of transformational generative grammar started arguing, with the support of a great deal of empirical evidence, that the notion of deep structure as formulated by the standard theory was not deep enough and that it needed to be refined $\mathrm{n}$ terms of 'deeper' semantic relations.

Such an a statement modifies the above mentioned statements that from within the same framework who were working with Chomsky have tried to develop this approach from one side but from the other side they lead to the collapse of the basic theory founded by Chomsky.

Moreover, Swan (2005) discusses in details the advantages of TGG in relations to the notion of universal grammar (UG), but later on he comes to the decision that "since 1950s, generative grammar has gone through numerous transformations, as grammarians have sought to reduce the complexity of their models while doing justice to the linguistic facts... despite recent radical changes and the development of Chomsky's Minimalist Programme, it is not clear that the enterprise has succeeded", (Swan, 2005: p. 76).

Presenting the history and development of linguistics, Schendl (2001) comes to the collusion that TGG has proved successful for some decades but later on it collapsed. He mentions "in spite of the obvious attractions of these explanations" he means explanations given by Chomsky and his followers "... many of its general axioms have been criticized on theoretical grounds, and some of the explanations of specific changes, such as the development of English models form full verbs, have been shown not to be substantiated by textual evidence”, (ibid: p. 71).

Once again and as mentioned earlier, Chomsky's approach was criticized for its focus on syntax and giving it more importance rather than the other components of language. This point is modified by Widdowson's statement “one objection to Chomsky's model is that it defines the nature of linguistic knowledge too narrowly to mean a knowledge of grammatical form and more specifically of syntax", (1996: p. 27).

Furthermore, Lehmann (1972) believes that it has become difficult to determine the most suitable approach for handling the problems of language, namely grammar. He assumes that case grammar is the most appropriate one that can be applied. Yet, he turns the fall of TGG and not being able to handle such matters for that "transformational grammar has come under heavy attack for its focus on ideal language rather than on the varied language of society... the attack emanated in great part from sociolinguists", (ibid: p. 51).

Well, some linguists and researchers will turn the reason of the fall of this approach for some particular observations which they have tested and found that this approach was not capable of providing such information and answers of their inquiries. Dryer (n. d) conducted a research 
paper arguing that a descriptive theory is totally different from an explanatory theory. He maintains that by a descriptive theory such as structuralism, we investigate how a language looks like and by an explanatory theory such as functionalism; we investigate why the language looks like this or that particular way. He then comes to the conclusion that "the reason why Chomskyan generative approaches have found linguistic basic theory inadequate is not in general that it fails to provide adequate descriptions, but that it fails to provide adequate explanations”, (ibid: p. 10).

In contrast with Montague grammar approach, Kao (2004) attempts to prove the superiority of the Montague grammar and its adequacy to prove information and answers which TGG could not do so. He illustrates this point by the argument between the two approaches from the same Chomskyan framework: interpretive semantics and generative semantics. For interpretivists drew a distinction between both syntactic rules and semantic ones whereas generative semanticists didn't do so. Most importantly, he considers that Montague grammar offered a solution that can relate semantics and syntax without connecting their rules.

In their review article of Marcus Tomalin’s book (2006), Scholz and Pullum (n. d.) clarify how it is difficult to discuss and collect the history of generative linguistics. Most importantly, they show how Tomalin attempts to explain the influence of generative grammars by both mathematics and logic. The question whether Chomsky's theory in particular can be considered as a science is raised. Consequently, the argument is that some consider it as a pure linguistic science and some others will reject such an ideas claiming that such a theory has proved inadequate in some linguistic matters and it can be considered only as a theory rather than a science.

More than that Zipf (n. d.), argues in his book against the Chomskyan notion and theory for mixing between what is originally semantic and originally syntactic. He attempts to prove that Chomsky's theory is biased more towards syntactic interpretation and representation. He states “ the problem with such theories stems an understandable but mistaken desire to keep the rules of syntax and the surface structures that are implicit in syntactic derivation as close as possible to those that manifested in the meaning representation”, (ibid: p. 2).

Eisner (n. d.), presents in a very complex way which actually pure-mathematics-like how TGG approach can help a lot in developing many programs especially in the case of natural languages dealing with computers and technology. In spite of this, he mentions that is only the complexity of this theory and its relation to mathematical and logical concepts which make it rejected by many linguists who are not qualified enough in mathematics and logic.

Steiner (1981) in his paper presenting nearly all the theories of language and its grammar, indicates that "Professor Emmons Bach suggests that Chomsky may be guilty of superficiality in 
comparing deep structures, even by analogy, with 'atomic facts' of grammatical relation”, (ibid: p. 13).

One more point directed against TGG is that it cannot be used for pedagogical purposes and it does not relate directly to English language teaching methodology. It is unlike both traditional and structural grammars which have so much to do in the language teaching methodology. Such a reason has given a chance to both approaches to be used even if they are rejected by some linguists and theorists. In his study, however, Abushibab (2008) makes a distinction between structuralism and TGG and their adequacy to be used for teaching and pedagogical purposes. He (ibid: p. 12) concludes his paper with that:

Transformational Grammar is not concerned with English teaching methodology. There are no teaching procedures of Transformational Grammar that can be converted into teaching procedures, but it gives implicit assumptions about language teaching. We can deal with such assumptions to derive some teaching English methodology.

To conclude, all the above mentioned reasons are considered as spots of weakness in this approach and have contributed to the collapse (FALL) of this approach.

\section{CONCLUSION}

This paper aimed at investigating two issues about one type of the grammatical approaches which TGG. The two main points are the rise of this approach opposed to the fall of this approach. The paper has been divided into five sections: section one contains a brief introduction to this term paper and its main ideas in general. Section two is divided into two parts: the 1st part contained of a theoretical background about transformational generative grammar. That is to say, how it is defined and viewed from the point of view of its proponents and at the same time some experts and specialists. Part two in section two, the researcher has attempted to design some charts to clarify statistically some points in numbers about the main idea of this paper which is the rise and the fall of TGG. In section three, the researcher moved to the core of this paper discussing the main reasons which caused for the rise of this approach. It has been shown, however, the major reasons for the rise of this approach are due to its innovativeness and the ability to handle many problems of language which other approaches were not able to handle. Above all is the continuous and at the same time numerous modifications which enabled it to cope with many linguistic problems. In section four, the opposite point is discussed. That is, the reason behind the fall of TGG. And the researcher came out with a number of the inferred reasons which has been considered as spots of weakness in this approach. Among these reasons as pointed out in this section are the interrelation of this approach to other fields such as mathematics and logic which make it difficult and complex from the point of view of some linguists. In addition, the many divisions of this approach or school to sub-schools, most importantly the generative semantics. Moreover, the appearance of other approaches which 
proved more adequate than Chomsky's grammar especially those which emerge as reaction to Chomsky's approach, has also contribute to the collapse of this approach.

For all intents and purposes, it has been shown throughout this paper that there are many advantages of this approach which cannot be denied by anyone. At the same time, there are some faults and spots of weakness which cannot be accepted and have been rejected which finally lead to the fall of this approach.

\section{REFERENCES}

Abushibab, İ. (2008). Can Transformational Generative Grammar Be Used for Pedagogical purposes? Retrieved from http://search.epnet.com accessed at 20/04/2009.

Al-Khuli, M. A. (1979). A contrastive Transformational Grammar: Arabic and Englsih. (G. F. Pijper, Ed.) Belgium: Lieden, E. J. Brill.

Allen, J. P. (Ed.). (1971). Chomsky: Selected Readings. London, New York, Toronto: Oxford Uinverstiy Press.

Ambrose-Grillet, J. (1978). Glossary of Transformational Grammar. Rowley, Mass: Newbury House Publishers, Inc.

Anttila, R. (1977). Trends in Linguistics. The Hague, Paris, New York: Mouton Publishers.

Atkinson, M. (1982). Foundations of General Linguistics. Boston, Sydney, London: George Allen \& Uniwin Publishers.

Bierwisch, M. (1971). Modern Linguistics. The Hague. Paris: Mouton.

Brown, K. (1984). Linguistics Today. Fontana: Fontana paperbacks.

Byram, M. (Ed.). (2004). Routledge Encylopedia of Language Teaching and Learning. London and New York: Routledge Taylor \& Francis Group.

Chomsky, N. (1965). Aspects of the Theory of Syntax. Cambridge, MA: MIT Press.

Chomsky, N. (1968). Language and Mind: Linguistic Contributions to the Study of Mind (Future).From:http://www.marxists.org/reference/subject/philosophy/works/us/chomsky.ht $\mathrm{m}$, accessed at 21/04/2009.

Chomsky, N. (1981). Lectures on Government and Binding. The Hague: Mouton.

Chomsky, N. (1957). Syntactic Structures. The Hague: Mouton.

Chomsky, N. (1995). The Minimalist Program. Cambridge, MA: MIT Press.

Collinge, N. E. (Ed.). (1990). An Encyclopedia of Language. London: Routledge.

Crystal, D. (1997). A Dictionary of Linguistics and Phonetics (4th Ed.). Blackwell: Blackwell Publishing.

Dryer, M. S. (n.d). Descriptive Theories, Explanatory Theories, and Basic Linguistic Theory1. From:http://linguistics.buffalo.edu/people/faculty/dryer/dryer/desc.expl.theories.pdf, accessed at 20/04/2009.

Eisner, J. (n.d). Transformational Priors Over Grammars. Retrieved from http://altavista.com. On Empirical Methods in Natural Language Processing (EMNLP 2002), Philadelphia, July 2002.

Helbig, G. (2007). Entwicklung der Sprachwissenschaft seit 1970 (Language Science Progress since 1970). (P. S. Buhairy, Trans.) Cairo: Zahra'a Al-Sharq.

Johnson, K. (Ed.). (1998). Encylopedic Dictionary of Applied Linguisitcs. Blackwell: Blackwell Publishing.

Kao, A. H. (2004). Montague Grammar. Retrieved from http://wwwpersonal.umich.edu/ akao/NLP_Paper.htm, accessed at 20/04/2009. 
LaPalombara, L. E. (1976). An Introduction to Grammar: Traditional, Structural, Transformational. Cambridge, Massachusetts: Winthrop Publishers, Inc.

Lehmann, W. P. (1972). Descriptive Linguistics: An Introduction (2 Ed.). New York: Random House.

Lester, M. (1976). Introductory Transformational Grammar of English. New York, Chicago, San Francisco, Atlanta, Dallas, Montreal, Toronto, London, Sydney: Holt, Rinehart and Winston.

Malmkjær, K. (Ed.). (2006). The Linguistics Encyclopedia. London and New York: Taylor \& Francis Group, Routledge.

Piattelli-Palmarini, M. (Ed.). (1980). Language and Learning: The Debate between Jean Piaget and Noam Chomsky. Cambridge, Massachusetts, Harvard University Press.

Quirk, R. (2002). A Grammar of Contemporary English. Retrieved from: http://mizian.com.ne.kr/englishwiz/library/goce/goce.htm, accessed at 21/04/2009.

Richards, J. C. (1992). Longman Dictionary of Language Teaching and Applied Linguistics. Longman: Longman University Press.

Schendl, H. (2001). Historical Linguistics: Oxford Introductions to Language Study. (H. G. Widdowson, Ed.) Oxford: Oxford University Press.

Scholz, B. C. (n.d). Tracking the origins of transformational generative grammar1. Retrieved from http://people.ucsc.edu/ pullum/scholz/Tracking.pdf, accessed at 20/04/2009. Cambridge: Cambridge University Press.

Scovel, T. (1998). Psycholinguistics: Oxford Introductions to Language Study. (H. G. Widdowson, Ed.) Oxford: Oxford University Press.

Steiner, G. (1981). "Whorf, Chomsky, and the Student of Literature 1974." In On Difficulty and Other Essays, 137-63. . New York, Oxford: Oxford Uinversity Press.

Swan, M. (2005). Grammar: Oxford Introductions to Language Study. (H. G. Widdowson, Ed.) Oxford: Oxford University Press.

Thakur, D. (2001). Syntax. Thakurbari Road, Kadamkuan, and Patna 800 003: Bharati Bhawan publishers \& Distributers.

Trask, R. L. (1992). A Dictionary of Grammatical Terms in Linguistics. London and New York: Routledge.

Trask, R. L. (Ed.). (2007). Language and Linguistics: The key Concepts (2nd ed.). RoutledgeFrancis \& Taylor: Roultledge Press.

Wales, K. (2001). A Dictionary of Stylistics. London, New York, Reading, San Francisco: Pearson Education Longman.

Widdowson, H. G. (1996). Linguistics: Oxford Introductions to Language Study. (H. G. Widdowson, Ed.) Oxford: Oxxford University Press.

Yule, G. (2006). The Study of Language (3 Ed.). Cambridge: Cambridge University Press.

Zipf, G. K. (n.d). Introduction. In G. K. Zipf, The Psychobiology of Language. Retrieved from:http://mitpress.mit.edu/books/chapters/0262194201chap1.pdf, accessed at 21/04/2009. 